\title{
Screening for refractive errors at age 1 year: a pilot study
}

\author{
R. M. INGRAM, M. J. TRAYNAR, C. WALKER, AND J. M. WILSON \\ From the Kettering and District General Hospital, Kettering
}

SUMMARY Cycloplegic refraction of 1-year-old children is technically possible and is acceptable to mothers as a method for screening children for visual defects. The range of refractions found in a sample of 186 1-year-old children is reported. Prediction of which children are significantly at risk for squint and/or amblyopia is possible on the basis of refractions at age 1 year according to the criteria selected for an 'abnormal' refraction. Bilateral hypermetropia and/or astigmatism or anisometropia at age 1 year was significantly $(P<1$ in 10000$)$ associated with a child eventually being found to have squint or amblyopia. Both the age of screening and the criteria of abnormality will probably need modification. +2.50 or more $\mathrm{D}$ hypermetropia in any one meridian of either eye at age 1 year was even more significantly $(P=0.00000005 \%)$ associated with squint and/or amblyopia. The possibility that meridional hypermetropia could be the basic defect in squint and amblyopia is discussed.

Thomson (1924) believed that 'our object and ideal should be the correction of the refractive error before the squint occurs', and Chavasse (1932) thought that if this was done 'before the time when the infant's visual reactions assume primatial characteristics, it would prevent the development of squint'.

However, identification of children in whom squint might reasonably be predicted must precede any preventive treatment, and Kramar (1973) concluded that refraction might be the best way of doing this. Screening should include children not known to have a family history of squint or amblyopia and must certainly be carried out before the age of 3 years, because this is the first peak age when children present with esotropia (Ingram 1977a). The age of 1 year was chosen for this study simply because we thought it would be technically easier to refract at that age rather than later. It remains to be seen, however, whether this is young enough, that is, within the sensitive period.

The study was designed (1) to find out if cycloplegic refraction of 1-year-old children was technically possible and acceptable to parents, and, if so, (2) to determine the range of refractions that might be found at this age.

Address for reprints: $\mathrm{Dr}$ R. M. Ingram, Kettering and District General Hospital, Rothwell Road, Kettering, Northamptonshire NN16 8UZ
We have delayed reporting our findings in order to have some indication of how effective the procedure might be in terms of predicting visual problems. This meant that we had to wait until the children had attained the age of $3 \frac{1}{2}$ years at least. Since this was a direct test of Kramar's (1973) suggestion, the results could be published coincidentally with another test of this principle in preschool siblings of children known to have squint and/or amblyopia (Ingram and Walker, 1979).

\section{Sample of children}

We visited the premises of 2 general medical practices at the same time as 1-year-old children were attending for immunisation. Since the children were 'called' by a computer for immunisation, we knew exactly how many children could potentially have been screened. $72 \%$ attended, and the mother of each of these children was offered the opportunity to have her child's eyes 'screened'. Only 4 of these declined, and overall $69 \%$ of those theoretically available were examined-a total of 186 children.

\section{Methods}

Retinoscopy of each child was performed 30 minutes after several drops of Cyclogyl $1 \%$ had been instilled into both eyes and the refraction recorded according to the principles suggested by Ingram 
Table 1 Refraction of children at age 1 year

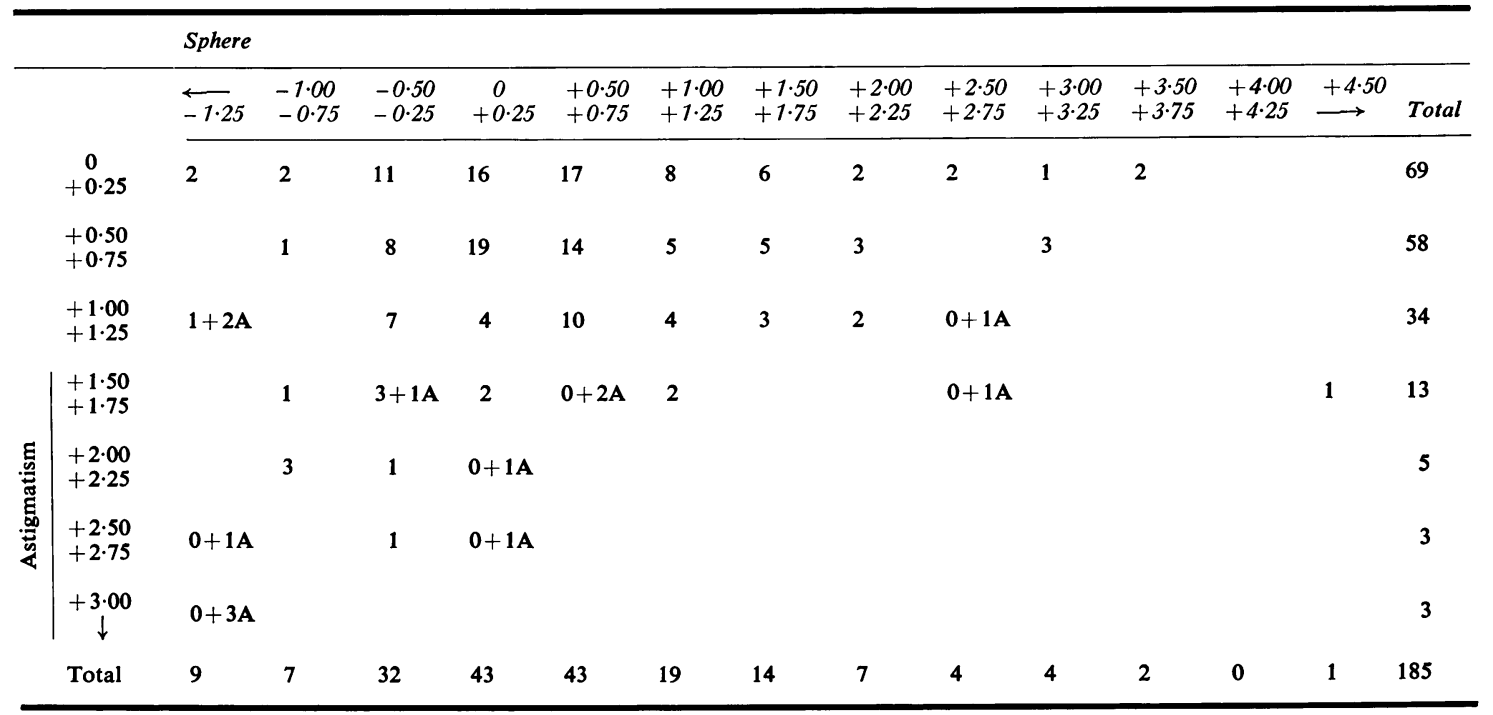

$\mathbf{A}=$ child with anisometropia

(1977b). If the pupils were not dilated after 15 minutes, or if the refraction seemed to vary during retinoscopy, more drops of Cyclogyl were instilled and retinoscopy carried out 30 minutes after this. All the refractions were performed by the same person (R. M. I.).

Those children found to have 'abnormal' refractions were followed up. Some of them were given spectacles at a later date, and we accept that this was not a wise or correct method of handling the problem in the absence of an established visual abnormality, such as squint or defective visual acuity.

\section{Final assessment}

An attempt was made to review all the children at the age of $3 \frac{1}{2}$ years. Visual acuity was recorded then or as soon as possible after that, using the Linear Sheridan-Gardiner test. The criteria for what was regarded as normal or abnormal vision were the same as those chosen for the assessment of preschool siblings (Ingram and Walker, 1979), that is, a child was assessed as 'abnormal' if there was any one or more of the following findings: (1) esotropia or exotropia detectable by the cover test; (2) visual acuity of $<6 / 12$ in either or both eyes, with correction if necessary; (3) a difference of $>1$ line between the acuity of the 2 eyes.

We accept that the choice of these criteria could be criticised, but recording of visual acuity in children of this age is not always reliable; for example, a child might admit to seeing only $6 / 12$ and yet have normal acuity or amblyopia. More than one attendance was necessary for some of the children. Also, we recognise that it is possible for a child of $3 \frac{1}{2}$ to show no signs of strabismus and yet later present with an (accommodative) esotropia. This happened with 2 children. Both were initially credited with 'normal' vision but reappeared at 5 years of age with a manifest left esotropia and have been recorded as 'abnormal'.

\section{Findings}

It was impossible to refract or assess the vision of 1 child because of gross congenital abnormalities. The refractions of 185 children at age 1 year are shown in Table 1 , where they are recorded on the basis of the spherical refraction of the more myopic or emmetropic eye and the maximum amount of astigmatism (recorded as +cylinders) found in either eye. $A$ indicates a child who had what we have regarded as a 'significant' amount of anisometropia, that is, +1.00 DS and/or +1.00 D cyl. difference between the refraction of the 2 eyes.

Fifteen of these children did not reattend for assessment at age $3 \frac{1}{2}$ and 17 others had moved away from this area. Thus, we have re-examined 153 of the original sample of children. We were unable to assess the vision of 4 of these and the refraction of 5 of them.

The refractions of the individual eyes of the 148 children who were refracted on both occasions are 
Table 2 Refraction of individual eyes of 148 children at age 1 year

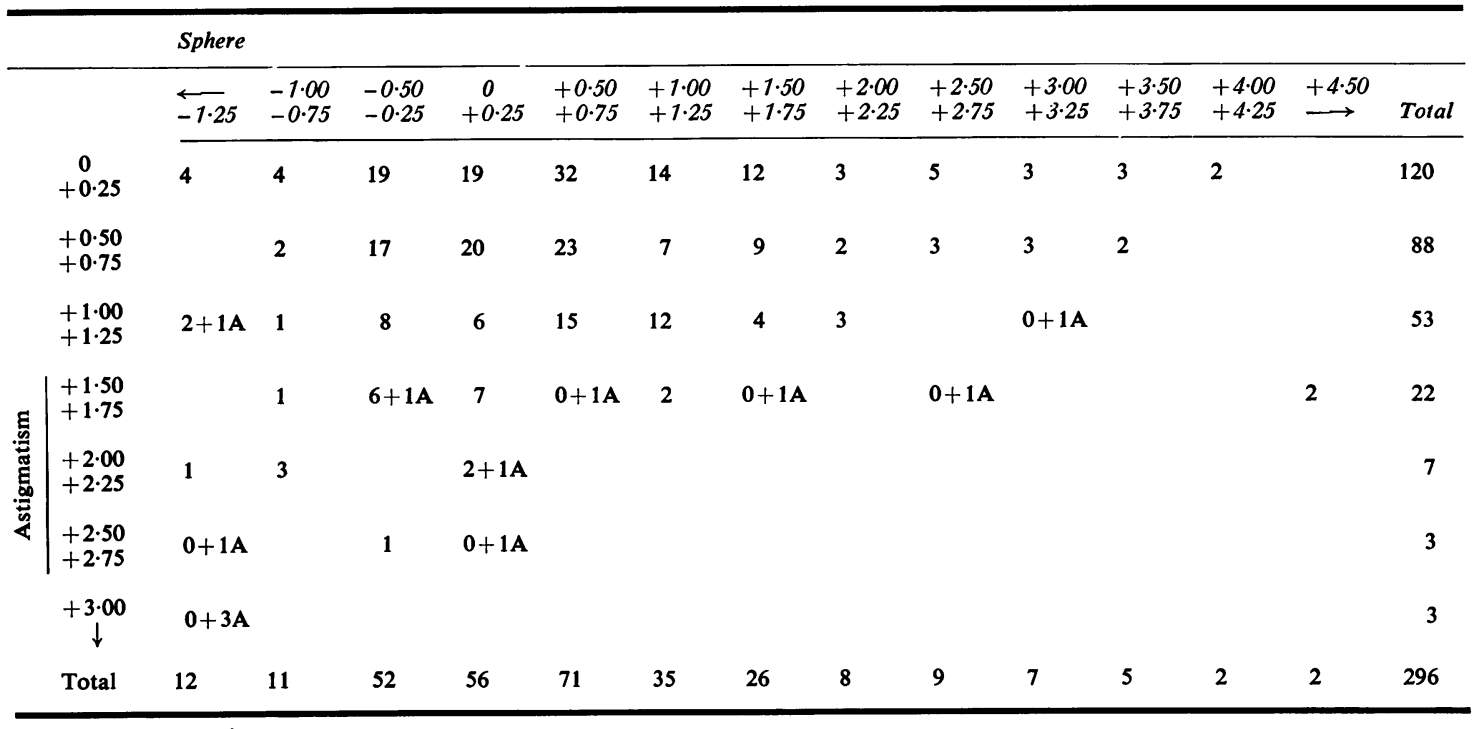

$\mathbf{A}=$ an anisometropic eye

Table 3 Refraction of individual eyes of 148 children repeated at age $3 \frac{1}{2}$ years

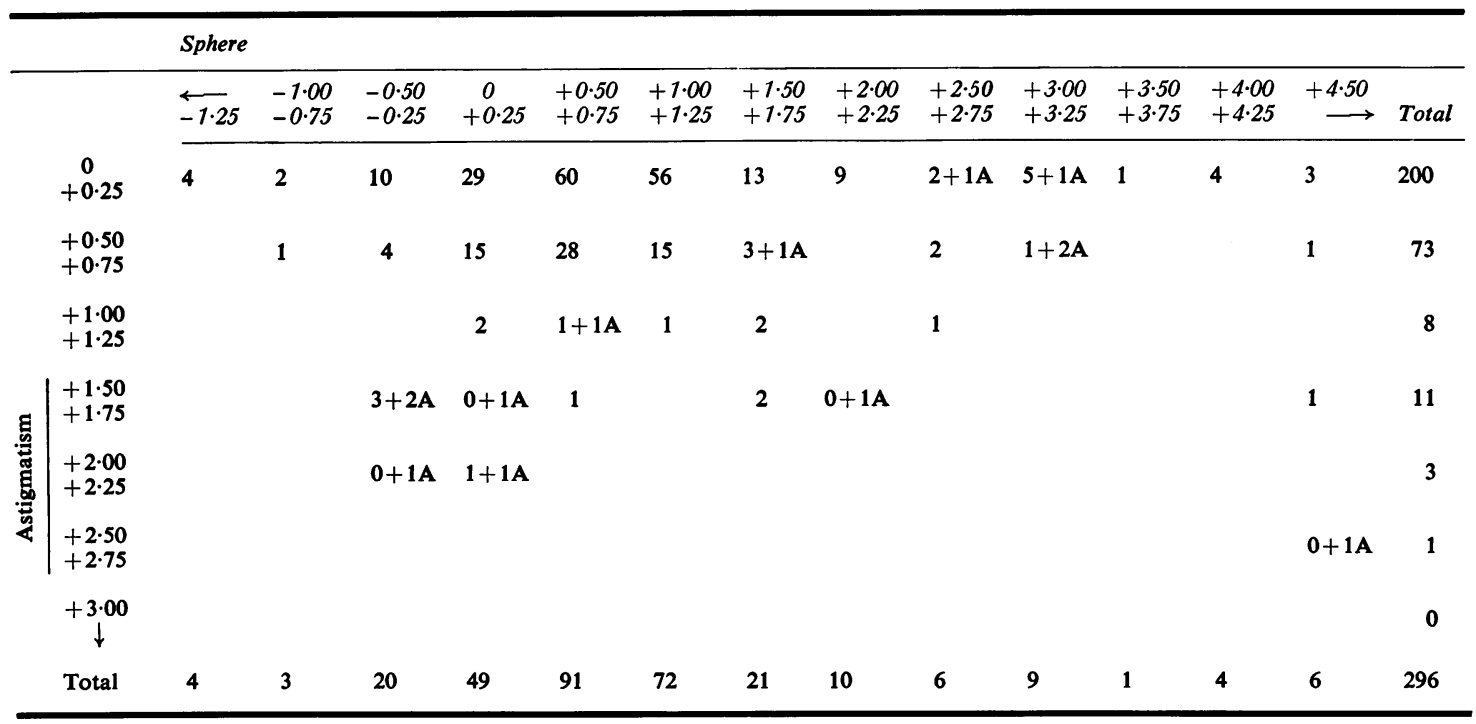

$\mathbf{A}=$ an anisometropic eye

summarised, on the basis described above, at age 1 year (Table 2) and $3 \frac{1}{2}$ years (Table 3 ). $A$ indicates an anisometropic eye. Of the 149 children whose vision we assessed 7 had esotropia, 1 had exotropia, 5 had amblyopia and microtropia, and 2 had amblyopia without a microtropia.

We have not published the refractions and visions of all the individual children, but we would be happy to supply photocopies of the details to interested enquirers.

\section{Discussion}

There is no doubt that it is technically possible to screen (by refraction after cycloplegia) children as young as 1 year old. The procedure seemed to be 
acceptable to parents $(96 \%$ of those to whom it was offered accepted), and later experience has confirmed this. As most children now have their hearing checked at the age of 9 months, it is natural that their vision should be screened at about the same age.

RANGE AND INCIDENCE OF REFRACTIONS FOUND AT AGE 1 YEAR

A curve representing the range of refractions found at age 1 year was roughly similar to that of Fabian (1966), who refracted children between the ages of 1 and 2 years, and it is similar in shape to that found in another sample of 1-year-old children refracted after atropine cycloplegia (Ingram and Barr, 1979b). It is more peaked and has a narrower spread than similar curves representing the refractions of newborn children (Cook and Glasscock, 1951; Graham and Gray, 1963; Goldschmidt, 1969).

The incidence of spherical hypermetropia and/or anisometropia $(15.6 \%)$ is slightly less than was expected (Ingram, 1977b). The incidence of hypermetropic astigmatism was $12.9 \%$, and this may be important. We were surprised to find that the axis of astigmatism, when recorded as +cylinders was in the (nearly) horizontal axis as often as it was in the (nearly) vertical axis (Table 5).

VISUAL ASSESSMENT AT $3 \frac{1}{2}$ YEARS OF AGE We are uncertain about the vision of 4 children, and 1 other child had such gross congenital abnormalities that we thought he should be excluded altogether, but we have been able to assess the vision of 149 of the original sample. Fifteen of these $(10 \%)$ have shown signs of squint and/or amblyopia,

Table 4 Summary of findings of refractions at age 1 year

\begin{tabular}{ll}
$\begin{array}{l}\text { Number of children with bilateral hypermetropia } \\
+2.00 \text { or more DS }\end{array}$ & $=18=9.7 \%$ \\
$\begin{array}{l}\text { Number of childred with astigmatism }+1.50 \text { or } \\
\text { more } D \text { in one or both eyes }\end{array}$ & $=24=12.9 \%$ \\
$\begin{array}{l}\text { Number of children with anisometropia } \\
\begin{array}{l}\text { Number of children with bilateral hypermetropia } \\
\text { and/or anisometropia }\end{array}\end{array}$ & $=29=13=7.0 \%$ \\
\hline
\end{tabular}

Table 5 The axis of astigmatism when this was recorded as + cylinders

\begin{tabular}{lll}
\hline & Horizontal & Vertical \\
\hline$+0.50 /+0.75 \mathrm{D}$ & 57 & 55 \\
$+1.00 /+1.25 \mathrm{D}$ & 27 & 32 \\
+1.50 or more D & 27 & 10 \\
\hline
\end{tabular}

Table 6 Possibility of predicting visual outcome: hypermetropia and/or anisometropia at age 1 year

\begin{tabular}{lccc}
\hline & Normal vision & Amblyopia & Total \\
\hline Normal refraction & 119 & 4 & 123 \\
Abnormal refraction & 15 & 11 & 26 \\
Total & 134 & 15 & 149 \\
\hline
\end{tabular}

$\chi^{2}=31.97 . \quad$ DF $=1 . \quad P=0.0000015 \%$

and possibly one or two others may yet develop manifest squint. We expected to find an incidence of about $7 \%$. The slightly higher percentage might be due to our sample being atypical of the population, but we cannot prove or disprove this.

POSSIBILITY OF USING REFRACTION AS A MEANS OF PREDICTING SQUINT/AMBLYOPIA As with the sample of preschool siblings (Ingram and Walker, 1979) we have found a highly significant association between the identification of bilateral hypermetropia and/or anisometropia and the future detection of squint and/or amblyopia (Table 6, $\mathbf{P}=0.0000015 \%$ ). Again, it is true that we have not predicted correctly in the case of all the children. In fact we have predicted only 11 out of the 15 recorded as 'abnormal', that is $73 \%$.

There are 5 possible explanations why we have not predicted more accurately: (1) Cyclogyl did not give sufficient cycloplegia (see Ingram and Barr, 1979b); (2) the refraction was incorrectly carried out; (3) the criteria for an abnormal refraction were wrongly selected (see alternatives later in this paper); (4) the refractions at age 1 year do not accurately reflect the refraction during the crucial part of the sensitive period, if this is earlier in life; (5) the basic cause of squint/amblyopia is not a refractive error leading to blurred vision during the sensitive period but a genetically determined neurological abnormality, as suggested by Wiesel and Hubel (1974). At present we think that (4) is the probable explanation.

\section{ANISOMETROPIA}

We have been interested in anisometropia since Ikeda and Wright (1975) suggested that it could cause stimulus-deprivation amblyopia if it was present during the sensitive period. Although he did not define what he meant by anisometropia, Lukaszewicz (1972) identified it at age 1 year, but Kubistova (1968) failed to find anisometropia at age 7 months and thought it 'appeared' between then and $3 \frac{1}{2}$ years. If this was so, it would, of course, eliminate Ikeda and Wright's (1975) hypothesis.

We found that $7.0 \%$ of our children had anisometropia at age 1 year, but, what is more important, 
we found that anisometropia both 'disappeared' and 'appeared' between the ages of 1 and $3 \frac{1}{2}$ years. Of the 12 children who had anisometropia at age 1 year 7 no longer had it at age $3 \frac{1}{2}$. None of these children had amblyopia, and at first sight this argues against Ikeda and Wright's (1975) theory, but we do not know whether they were anisometropic earlier in life, for example, during the first 3 months, and only 2 of them had significant hypermetropia $(+2.50 \mathrm{D})$ in any one meridian at age 1 year (see later). Eight children who did not have anisometropia at age 1 year had anisometropia at $3 \frac{1}{2}$. Five of these did not have amblyopia, and in clinical practice anisometropia is not invariably associated with amblyopia. Only 2 of them had $+2 \cdot 50 \mathrm{D}$ in any one meridian (see later). We do not know whether the 3 who were amblyopic had anisometropia before the age of 1 year, but in fact 2 of the 3 had $+2.50 \mathrm{D}$ in one or more meridia at age 1 year (see later).

CRITERIA FOR AN ABNORMAL REFRACTION Bilateral hypermetropia and/or anisometropia were originally selected as criteria for an abnormal refraction because these are the refractions traditionally regarded as being associated with squint/ amblyopia.

It would have been foolish not to have looked, in retrospect, at other possible refractions that could be regarded as abnormal. Mindful of the acceptance (von Noorden, 1974) of meridional amblyopia (Mitchell et al., 1973) as a form of stimulusdeprivation amblyopia, and thinking that anisometropic amblyopia could also be a form of stimulusdeprivation amblyopia, we looked for and found a very close association between astigmatism and anisometropia in 1-year-old children (Ingram, 1979). This finding was confirmed in preschool siblings of children who presented to us with squint/amblyopia (Ingram and Walker, 1979) in this series of children both at age 1 and $3 \frac{1}{2}$ (Ingram and Barr, 1979a), and in children as they present with visual defects (unpublished data). This led us to consider hypermetropia and/or astigmatism of +2.00 or more $D$ in either eye at age 1 year as being a possible pointer to identifying children who will eventually present

Table 7 Possibility of predicting visual outcome: hypermetropia and/or astigmatism +2.00 or more $D$

\begin{tabular}{llcc}
\hline & Normal vision & Amblyopia & Total \\
\hline Normal refraction & 119 & 5 & 124 \\
Abnormal refraction & 15 & 10 & 25 \\
Total & 134 & 15 & 149 \\
\hline$\chi^{2}=25.89$ & DF $=1$ & $\mathrm{P}=0.000036 \%$ &
\end{tabular}

Table 8 Meridional hypermetropia at age 1 year and prediction of squint/amblyopia

(a) +2.00 or more $\mathrm{D}$ in any one (or more) meridian

\begin{tabular}{lccc} 
& Normal vision & Amblyopia & Total \\
\cline { 2 - 4 } Normal refraction & 108 & 2 & 110 \\
Abnormal refraction & 26 & 13 & 39 \\
Total & 134 & 15 & 149
\end{tabular}

$\chi^{2}=28 \cdot 20 . \quad$ DF $=1 . \quad P=0.000011 \%$

$86 \%$ of squint/amblyopia in $26 \%$ of the population

(b) +2.50 or more $\mathrm{D}$ in any one (or more) meridian

\begin{tabular}{lccc} 
& Normal vision & Amblyopia & Total \\
\cline { 2 - 4 } Normal refraction & 124 & 3 & 127 \\
Abnormal refraction & 10 & 12 & 22 \\
Total & 134 & 15 & 149
\end{tabular}

$\chi^{2}=50.78 . \quad \mathrm{DF}=1 . \quad \mathrm{P}=0.00000005 \%$

$80 \%$ of squint/amblyopia in $14.9 \%$ of the population

(c) +3.00 or more $\mathrm{D}$ in any one (or more) meridian

\begin{tabular}{lccc} 
& Normal vision & Amblyopia & Total \\
\cline { 2 - 4 } Normal refraction & 129 & 7 & 136 \\
Abnormal refraction & 5 & 8 & 13 \\
Total & 134 & 15 & 149
\end{tabular}

$\chi^{2}=35.68 . \quad \mathrm{DF}=1 . \quad \mathrm{P}=0.00000022 \%$

$53 \%$ of squint/amblyopia in $8.7 \%$ of the population

with squint and amblyopia, and there is a significant association between these two conditions (see Table 7, $\mathrm{P}=0.000036 \%$ ).

It seemed logical to follow this by considering not only the refractions of individual eyes but the refraction in individual meridia of individual eyes. If one looks at this from the point of view of the level of hypermetropia in one or more meridia of a pair of eyes, an interesting association emerges (Table 8 ): $86 \%$ of those children who were eventually found to have squint/amblyopia were among $26 \%$ of the children screened who had +2.00 or more D in one (or more) meridia at age 1 year. $80 \%$ of those who had squint/amblyopia were among $14.9 \%$ of the children who had +2.50 or more $D$ in one or more meridia at age 1 , and a child who had +3.00 or more $\mathrm{D}$ in any one meridian had a slightly better than even chance of eventually having squint/ amblyopia. Thus, meridional hypermetropia appears to be more significantly associated with the eventual identification of squint/amblyopia than bilateral hypermetropia and/or anisometropia or astigmatism. The lower level of meridional hypermetropia $(+2 \cdot 00$ D) will detect the highest percentage of children 
who are destined to have a visual problem, but is the least selective. +3.00 D of meridional hypermetropia is the most selective but would 'miss' half of those children who eventually have a defect. In between, there is the extremely highly significant association $(P=0.00000005 \%)$ between $+2.50 \mathrm{D}$ or more of hypermetropia in any one or more meridia at the age of 1 year and the eventual identification of squint and/or amblyopia. There can be very little doubt that Kramar's (1973) suggestion that we might be able to predict events on the basis of refraction was correct.

HYPERMETROPIA IN INDIVIDUAL MERIDIA When two factors are associated at this level of significance (less than 1 in 10 million chance) it is possible that they are one and the same thing or that one could be the cause of the other. If meridional amblyopia really is caused by stimulus deprivation, the possibility arises that stimulus-deprivation amblyopia, due to hypermetropia in any one (or more) meridia of either or both eyes in infancy, is the basic factor common to the whole range of childhood squint/amblyopia problems as they present to us. It is interesting to speculate on what could follow from this.

MERIDIONAL HYPERMETROPIA, STIMUL.US DEPRIVATION, AMBLYOPIA AND SQUINT

If you can have stimulus deprivation amblyopia in one meridian of each of a pair of eyes (meridional amblyopia explaining reduced acuity found with some bilateral hypermetropic astigmatic refractions), you can also have stimulus deprivation amblyopia in unilateral astigmatism (such an eye would be considered to be anisometropic) or in both the vertical and horizontal meridia of one and the same eye, with or without any combination of these in the fellow eye. If there is a period of life before which an eye can accommodate sufficiently to accurately focus light entering the eye(s) in all meridia (Haynes et al., 1965), there would be stimulus deprivation in either or both meridia of one and/or both eyes according to the hypermetropia (in one or more meridia) above which the eye(s) was capable of accommodating. Ikeda and Tremain (1978) have recently shown that unilateral or bilateral atropinisation during the sensitive period resulted in unilateral or bilateral amblyopia in kittens. In addition, Blakemore and Eggers (in press) have demonstrated in kittens a loss of spatial resolution of cortical cells driven from one of a pair of eyes artificially made hypermetropic during the sensitive period.

The amount of hypermetropia might be the important factor, for example, the bilateral amblyo- pia which is recognised in association with high spherical hypermetropic refractions. However, it is also possible that an astigmatic eye does not, or cannot, automatically accommodate for the more hypermetropic meridian if the less hypermetropic meridian is easily focused. Thus, the stimulus deprivation might be related to the amount of hypermetropia in the more hypermetropic meridian or a combination of this and the difference in hypermetropia between the two meridia of one (or both) eyes.

As the eye(s) developed the ability to accommodate, and/or if the eye(s) became less hypermetropic (in one or more meridia), any 'deprivation' would progressively become less and the stimulus required to develop or maintain the neuronal connections would develop. Clear visual stimulus would, therefore, depend on how quickly an eye developed the ability to accommodate for all meridia relative to the rate at which any hypermetropia in any one or more meridia decreased. If this is related to the duration of the sensitive period, we could imagine stimulus-deprivation amblyopia as being the end result of a combination of circumstances occurring, and changing, during the first weeks or months of life. Thus, hypermetropia (in one or more meridia) might be the cause of the basic defect (primary amblyopia) not because it caused excessive or unusual accommodation and therefore squint, but for precisely the opposite reason, namely, before the eye could accommodate sufficiently, such an eye would present a blurred picture to the brain.

Furthermore, if there was some degree of stimulusdeprivation amblyopia, unilateral or bilateral, there could also be some defect of binocular vision (a microtropia?). Only later, when accommodation was possible and required in order to obtain clear vision (that is, if both eyes or if the master eye had a spherical hypermetropic refraction) would there be an unusually marked tendency for hypermetropia to result in accommodation, which in turn would lead to manifest esotropia. This would then be superimposed on a basic defect of binocular vision, and, if the esotropia was uniocular and prolonged, a further set of circumstances could operate and lead to what we have called 'secondary' amblyopia (Ingram et al., 1977).

So far we have assumed that hypermetropia tends to decrease during the sensitive period, but there is no evidence for this yet, and an 'abnormal' amount of hypermetropia can increase after the age of 1 year (Ingram and Barr, 1979a). Moreover, an eye which originally had a normal refraction can occasionally become significantly hypermetropic in one or both meridia after the age of 1 year. We suggest that 
such an eye(s) originally presented no barrier to the normal development or maintenance of the cortical neurones, and therefore is not associated with amblyopia or any basic defect of binocular vision. If hypermetropia increased in one meridian of both of a pair of such eyes, we should have a child presenting with blurred vision and hypermetropic astigmatism. Correction of the refractive error would yield normal vision. Increase in hypermetropia in both meridia of both eyes would necessitate increased accommodation, and since accommodation is tied to convergence we could have, in the absence of previous stimulus deprivation, a child presenting with a wholly accommodative esotropia-one which would be cured by optical correction alone. Increase in hypermetropia in one or both meridia of only 1 eye could explain the 'straight-eyed anisometrope' who does not have any amblyopia. It would not be necessary to predict a child who would present under any one of the three above circumstances, since the 'defect' would be readily corrected optically. This would be in marked contrast to the need to identify abnormal hypermetropia present during the sensitive period, because such refractions might leave a permanent defect.

We do not claim that our hypothesis, based as it is on the relatively small number of children in this report, explains the enigma of squint/amblyopia. For example, it does not explain the essential alternator who presents before the age of 1 year, or the occasional accommodative esotropia of infancy (Pollard, 1976). Nevertheless, it could provide a new and different basis for further thought. If it was correct, then total cure would be possible only by correction of abnormal refractions during the sensitive period. If correction at a given age proved ineffective, then either the sensitive period had ended before the refraction was corrected, or, if it was ultimately found to be impossible to cure by this means, the cause of the visual defect must be something else, for example, a genetically determined absence of neurones.

We suggest, therefore, that investigation should proceed to: (1) identify the refraction that is most likely to lead to correct prediction of future visual defects, and therefore enable selection of children for trial of optical correction; (2) identify the age at which optical correction leads to a significant number of 'cures', and thus indicate when we are within the sensitive period in man.

We have started to do this, but think that the age of 1 year may be too late. We do not know of any reason why we should expect the duration of the sensitive period in man to be different from that of other mammals such as monkeys, and we recognise that the sensitive period may not end abruptly. Meanwhile, it would be helpful to know more about how refraction changes as children grow. Further, we need to know how effective cyclopentolate is as a cycloplegic and whether this is the drug of choice for this type of work.

We thank Drs K. I. Padget and D. W. Smith and their partners for permission to see their patients and use their practice premises for the initial screening. We also thank Miss Beaumont and Mrs Mills, their respective health visitors, for their co-operation and help, without which this investigation would not have been possible. We also thank Dr A. Barr for the statistical analysis and Mrs L. Neale for secretarial work.

The investigation was supported by a grant from the research funds of the Oxford Regional Health Authority.

\section{References}

Blakemore, C., and Eggers, H. (In press). Animal models for human visual development. In Proceedings of $a$ Dedicatory Symposium for the College of Optometry. University of Houston.

Chavasse, B. (1932). In. Symposium on non-paralytic squint. Transactions of the Ophthalmological Societies of the United Kingdom, 52, 348-352.

Cook, R. C., and Glasscock, R. E. (1951). Refractive and ocular findings in the newborn. American Journal of Ophthalmology, 34, 1407-1413.

Fabian, G. (1966). Ophthalmological serial examination of 1200 children in their second year of life. Acta Ophthalmologica, 44, 473-479.

Goldschmidt, E. (1969). Refraction in the newborn. Acta Ophthalmologica, 47, 570-578.

Graham, M. V., and Gray, O. P. (1963). Refraction of premature babies' eyes. British Medical Journal, 1, 14521454.

Haynes, H., White, B. L., and Held, R. (1965). Visual accommodation in human infants. Science, 148, 528-530.

Ikeda, H., and Wright, M. J. (1975). A possible neurophysiological basis for amblyopia. British Orthoptic Journal, 32, 2-13.

Ikeda, H., and Tremain, K. E. (1978). Amblyopia resulting from penalisation: neurophysiological studies of kittens reared with atropinisation of one or both eyes. British Journal of Ophthalmology, 62, 21-28.

Ingram, R. M. (1977a). The problem of screening children for visual defects. British Journal of Ophthalmology 61, 4-7.

Ingram, R. M. (1977b). Refraction as a basis for screening children for squint and amblyopia. British Journal of Ophthalmology, 61, 8-15.

Ingram, R. M. (1979). Refractions of 1-year-old children after atropine cycloplegia. British Journal of Ophthalmology, 63 (in press).

Ingram, R. M., and Barr, A. (1979a). Changes in refraction between the ages of 1 and $3 \frac{1}{2}$ years. British Journal of Ophthalmology, 63 (in press).

Ingram, R. M., and Barr, A. (1979b). Refraction of 1-yearold children after cycloplegia with $1 \%$ cyclopentolate: comparison with findings after atropinisation. British Journal of Ophthalmology, 63 (in press).

Ingram, R. M., Rogers, S., and Walker, C. (1977). Occlusion and amblyopia. British Orthoptic Journal, 34, 11-22.

Ingram, R. M., and Walker, C. (1979). Refraction as a means of predicting squint or amblyopia in preschool 
siblings of children known to have these defects. British Journal of Ophthalmology, 63, 238-242.

Kramar, P. O. (1973). The possibility of predicting the appearance of squint. British Orthoptic Journal, 30, 66-73.

Kubistova, V. (1968). Contribution to the genesis of anisometropia. Ceskoslovenská Oftalmologie, 4, 263-265.

Lukaszewicz, B. (1972). Examination of refraction up until third year of life. Klinika Oczna, 42, 833-835.

Mitchell, D. E., Freeman, R. D., Millodot, M., and Haegerstrom, G. (1973). Meridional amblyopia; evidence for modification of the human visual system by early visual experience. Vision Research, 13, 535-558.
Noorden, G. K. von (1974). Factors involved in the production of amblyopia. British Journal of Ophthalmology, 58, 158-164.

Pollard, Z. F. (1976). Accommodative esotropia during the first year of life. Archives of Ophthalmology, 94, 1912-1913.

Thomson, W. E. (1924). In: Symposium on squint. Transactions of the Ophthalmological Societies of the United Kingdom, 44, 238-252.

Wiesel, T. N., and Hubel, D. H. (1974). Ordered arrangement of orientation columns in monkeys lacking visual experience. Journal of Comparative Neurology, 158, 307318. 